\title{
Physical performance of elite wheelchair basketball players in armcranking ergometry and in selected wheeling tasks
}

\author{
Y Hutzler PhD
}

The Zinman College of Physical Education, The Wingate Institute, Netanya, Israel.

This study compared the aerobic and the anaerobic performance of 11 elite Israeli wheelchair basketball players in arm ergometric tests and corresponding wheeling tasks, derived from basketball practice. The ergometric tests included a continuous aerobic maximal peak work capacity test (PWCmax), and a 30-second arm-all-out anaerobic test of mean anaerobic capacity (MANC) and peak anaerobic power (PANP). The wheeling tasks included a 428 meter race, slalom and 6-minute endurance race. We examined the relationship of performance variables to personal variables, age, bodyweight and classification as athletes. The results were analysed by Spearman correlation tables, revealing the following: (1) HRmax (maximal heart rate) correlated highly $(r=.884-.962)$ with performance in all wheeling tasks; (2) no relationship was found between variables in the arm ergometric tests and variables in the wheeling tasks; (3) bodyweight correlated significantly with MANC and PWCmax $(r=.817$ and .783 respectively). This relationship was better than the other independent variables (classification and age). It is concluded that HRmax can be used for performance evaluation in wheelchair basketball practice, and that arm ergometric work capacity has only limited predictive value of performance in wheeling tasks.

Keywords: aerobic and anaerobic capacity; arm ergometry; wheelchair basketball; performance evaluation; physiological tests; spinal paralysis.

\section{Introduction}

Scientific study of the physical performance in wheelchair related tasks has generally been restricted to cardiorespiratory functions such as heart rate, maximal oxygen consumption, evoked respiratory volume, etc measured in laboratory settings and utilising some form of armcrank or wheelchair ergometers. These are fairly well documented in the literature. ${ }^{1.2}$

Most studies of this kind discuss only aerobic physiological phenomena, dealing with the effects of prolonged exercise bouts. Few studies have paid attention to anaerobic physiological phenomena measuring peak and mean power during short bouts of exercise..$^{3,4}$ Only limited information supports the applicability of ergometric measurements to daily and sports related activities of persons using wheelchairs for mobility. ${ }^{3}$

Therefore, the purposes of this study were: (1) to compare aerobic and anaerobic performance of elite Israeli wheelchair basketball players in standardised armcrank ergometric exercise and in corresponding wheeling tasks; and (2) to examine the relationship between performance in the ergometric and wheeling tasks and subjects' age, bodyweight and functional classification.

\section{Methods}

\section{Subjects}

Nine male elite wheelchair basketball players, members of the Israeli national team who were training at the time for the 1991 European championship, volunteered to participate in this study. Players' classification was determined according to the IWBF (International Wheelchair Basketball Federation) guidelines and varied between the most (one point) to the least severely 
functionally limited (4 points). The mean value of the players' classification was $2.94 \pm 1.12$ points. Their ages ranged from 25 to 46 (mean $33 \pm 6.18$ years). They weighed between 51 and $90 \mathrm{~kg}$ (mean $73.89 \pm 11.53 \mathrm{~kg}$.) Four had had poliomyelitis, 2 were paraplegic, and 3 were amputees.

\section{Procedure}

\section{Arm ergometry}

All subjects were tested by aerobic (PWCmax) and anaerobic (30 s) protocols, both utilising the same Fleish armcrank ergometer. The aerobic maximal capacity test (PWCmax) consisted of a continuous and progressive protocol starting with a $240 \mathrm{~g}$ resistance increasing by $240 \mathrm{~g}$ increments every 2 minutes to exhaustion. This procedure was reported to be highly valid and reliable. ${ }^{5,6}$ The load increment was chosen to allow for a sufficient number of loadings (usually 5 or 6 ) to precisely identify the breakdown point. The cranking device was fixed at subjects' shoulder height. The rate was set at $70 \mathrm{RPM}$. The anaerobic 30 -second arm-all-out test was performed with an identical protucol to the leg-all-out test, whose reliability was established previously. ${ }^{3}$ The resistance was determined relative to bodyweight at $25 \mathrm{~g} / \mathrm{kg}$.

Peak work capacity (PWC) and maximal heart rate (HRmax) during the PWCmax test were taken as measures of aerobic capacity. Peak 5-second mechanical output during the arm-all-out test represented peak anaerobic power (PANP). The mechanical output during this 30 -second test represented the mean anaerobic capacity (MANC). Power output within the last 5 seconds as a percentage of PANP represented the index of anaerobic fatigue (FI).

\section{Wheeling tasks}

All subjects participated in a series of three wheeling tasks, introduced as part of their exercise routine; (1) 6 minutes of continuous wheeling around an elliptical concrete track of $107 \mathrm{~m}$ circumference (min6). The distance covered was visually measured to the nearest $10 \mathrm{~m}$ along the track. This task was selected in order to give an estimate of the aerobic effort needed throughout a basketball match; (2) $428 \mathrm{~m}$ racing trials on the same elliptical track ( 4 rounds) in groups of 2 subjects (race). To complete this task the subjects required beween 2 and 3 minutes, which reflects the combined aerobic and anaerobic capacity needed for coping with successive shifts from offence to defence and vice versa; and (3) a unique wheelchair slalom parcours including 15 direction changes and four short sprints of $10 \mathrm{~m}$ each (slalom). The time was measured with a stop watch. This task lasted about one minute, and was used as a measure for lactic anaerobic effort needed during aggressive offensive and defensive drills. Depending on the duration of the wheeling tasks, we hypothesised that the slalom would correspond with PANP and MANC, the race with FI and PWC, min6 test with PWC.

All field tests were repeated twice within a period of 2 weeks in order to establish test-retest reliability coefficients.

\section{Statistical methods}

Spearman rank order correlation coefficients were computed between all the variables. Descriptive methods were implied in order to illustrate specific intervariable relationship.

\section{Results}

The individual physiological characteristics and wheeling performances measured are summarised in Table I.

Very high test-retest reliability coefficients were measured for the two short-term wheeling tasks $(r=.981$ for the slalom and .993 for the sprint, $p=.001)$, while the task min6 demonstrated a high reliability coefficient of $r=.872(p=.01)$.

Table II presents Spearman rank order correlation coefficients, computed between the personal and the performance variables.

Table II reveals significant $(p<.05)$ and relatively high correlation coefficients, computed between players' classification and their mean anaerobic capacity $(r=.717$, $p=0.15$ ) as well as between class and sprint results, which corresponded negatively $(r=-.641, p=.031)$. Bodyweight has high 
Table I Physiological characteristics and wheeling performance of Israeli elite wheelchair basketball players

\begin{tabular}{|c|c|c|c|c|c|c|c|c|c|c|c|}
\hline Subject & $\begin{array}{c}\text { Class } \\
\text { (points) }\end{array}$ & $\begin{array}{l}\text { Age } \\
(y r)\end{array}$ & $\begin{array}{l}\text { Weight } \\
\text { (kg) }\end{array}$ & $\begin{array}{l}\text { Manc } \\
\text { (watt) }\end{array}$ & $\begin{array}{l}\text { PANP } \\
\text { (watt) }\end{array}$ & $\begin{array}{l}\text { PWC } \\
\text { (watt) }\end{array}$ & $\begin{array}{c}\text { HRmax } \\
\text { (beat/min) }\end{array}$ & $\begin{array}{l}\text { FI } \\
\%\end{array}$ & $\begin{array}{l}\operatorname{Min} 6 \\
(\mathrm{~m})\end{array}$ & $\begin{array}{l}\text { Race } \\
(\mathrm{s})\end{array}$ & $\begin{array}{l}\text { Slalom } \\
\text { (s) }\end{array}$ \\
\hline 1 & 3.0 & 37 & 87 & 310.59 & 357.00 & 137.25 & 166 & 31.5 & 5615 & 157 & 56 \\
\hline 2 & 4.0 & 27 & 83 & 370.20 & 432.94 & 168.24 & 175 & 34.8 & 4815 & 162 & 59 \\
\hline 3 & 1.0 & 25 & 70 & 304.71 & 411.76 & 125.00 & 180 & 48.0 & 4494 & 172 & 66 \\
\hline 4 & 4.0 & 29 & 73 & 394.12 & 476.47 & 103.92 & 147 & 40.7 & 5992 & 150 & 53 \\
\hline 5 & 2.0 & 28 & 75 & 308.82 & 370.59 & 113.73 & 197 & 47.7 & 4494 & 169 & 63 \\
\hline 6 & 3.0 & 34 & 62 & 301.47 & 367.65 & 102.94 & 157 & 40.0 & 5564 & 160 & 56 \\
\hline 7 & 1.5 & 34 & 51 & 212.42 & 245.10 & 104.71 & 176 & 20.0 & 5243 & 170 & 61 \\
\hline 8 & 4.0 & 46 & 90 & 407.84 & 489.41 & 146.57 & 174 & 42.3 & NA & 165 & 58 \\
\hline 9 & 4.0 & 37 & 74 & 305.88 & 388.24 & 105.39 & 166 & 50.0 & 5277 & 162 & 58 \\
\hline Average & 2.94 & 33.00 & 73.89 & 324.01 & 393.24 & 123.08 & 170.89 & 39.44 & 4610.44 & 163.00 & 58.89 \\
\hline Standard & 1.12 & 6.18 & 11.53 & 55.93 & 68.76 & 21.87 & 13.45 & 8.98 & 1699.56 & 6.55 & 3.73 \\
\hline
\end{tabular}

$\mathrm{MANC}=$ mean anaerobic capicity $\mathrm{PANP}=$ peak anaerobic power; PWC = peak work capacity; $\mathrm{HRmax}=$ maximal heart rate; FI $=$ fatigue index; Min6 $=6$ min of continuous wheeling. 
Table II Spearman rank-order correlation matrix between personal and performance variables

\begin{tabular}{lrrrrrrrr}
\hline & MANC & PANP & \multicolumn{1}{c}{ FI } & \multicolumn{1}{c}{ PWC } & HR & Min6 & Race & Slalom \\
\hline Class & .717 & .612 & .096 & .184 & -.615 & .535 & -.641 & -.626 \\
& $p=.015$ & & & & & & $p=.031$ & \\
Age & .193 & -.092 & -.101 & -.025 & -.456 & .655 & -.316 & -.521 \\
Weight & .817 & .450 & .100 & .783 & .008 & .034 & -.234 & -.151 \\
& $p=.004$ & & & $p=.006$ & & & & \\
\hline
\end{tabular}

and significant $(p<.005)$ relationship with mean anaerobic capacity $(r=.817$, $p=.004)$ and maximal aerobic power $(r=.783, p=005)$. No relationship was found between bodyweight and performance in task specific wheeling exercise.

Spearman correlation coefficients were also computed beween all dependent variables as presented in Table III.

Table III demonstrates very high correlation coefficients between the individual wheeling tasks $(r=.884-.967, \quad p=$ $.002-.000)$. Maximal heart rate in the aerobic armcranking task was the only other dependent variable which demonstrated high correlations to results in these tasks $(r=.887-.962, \quad p=.002-.000$ respectively). One must notice that the min6 variable correlated negatively with heart rate which means that lower heart rate matched higher performance (in meters) measured. On the other hand, the race and slalom times correlated positively with the heart rate because both were measured in seconds which means that the lower time measured in these events matched the lower heart rate values measured in the aerobic armcranking exercise. The same applies to the results in all wheeling events, which correlated very highly with each other $(r=-.887$ to $-.967 p=.002$ to .000 respectively). Though the times of the race and sprint tests (mean $=59-163$ seconds) are generally related to anaerobic energy sources while the min6 test relates to aerobic energy sources, ${ }^{7}$ the correlations between variables of the min 6 and race tests measured in this study were higher $(r=-.967)$ than between the race and sprint times $(r=.941)$. MANC and PANP also correlated rather highly with each other $(r=.767, p=.008)$.

\section{Discussion}

This study compared two arm ergometric tests whose reliability was established and three wheeling tasks derived from wheelchair basketball exercise routines. The very high test-retest reliability coefficients measured, especially in the race and the slalom, suggests that they are a reliable tool

Table III Spearman rank-order correlation matrix within the performance variables

\begin{tabular}{|c|c|c|c|c|c|c|c|}
\hline & PANP & FI & PWC & HR & Min6 & Race & Slalom \\
\hline MANC & $p=.008$ & .100 & .533 & -.251 & .311 & -.426 & -.378 \\
\hline PANP & & .467 & .367 & -.142 & -.024 & -.100 & -.109 \\
\hline FI & & & .000 & .142 & -.344 & .251 & .260 \\
\hline PWC & & & & .427 & -.440 & .226 & .336 \\
\hline $\mathrm{HR}$ & & & & & $\begin{array}{r}-.936 \\
p=.000\end{array}$ & $p=.887$ & $p=.002$ \\
\hline Min6 & & & & & & $\begin{array}{r}-.884 \\
p=.002\end{array}$ & $\begin{array}{r}-.967 \\
p=.000\end{array}$ \\
\hline Sprint & & & & & & & 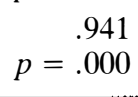 \\
\hline
\end{tabular}


for performance evaluation in wheelchair basketball.

In relation to differences in aerobic and anaerobic exercise we hypothesised that the effects of the min 6 continuous wheeling task would correspond to the effects of the aerobic armcranking test on PWC and HRmax, while the results in the sprint and the race tasks would correspond to the effects of the anaerobic test on MANC and PANP. The correlation matrix presented in Table III illustrates that no work capacity variable in the armcranking tasks had high correlation with any of the wheeling results $(r=-.440-.331)$. The only dependent variable having high correlations with the wheeling tasks was maximal heart rate measured during the aerobic armcranking exercise $(r=.887-.936)$. Interestingly, no similar relationship were found between heart rate and variables of armcranking performance (PWC, PANP and MANC). Correlation was very low $(r=.427,-.142$ and -.251 respectively). This suggest that heart rate measurements during exercise may be a valuable simple tool for the evaluation of physical fitness. It also highlights the difficulty in relating physiological response to work capacity during armcranking exercise in wheelchair subjects. This may be explained in part by the effort needed to stabilise the trunk during armcranking exercise. This stabilising effort activates the lower trunk, abdominal and hip muscles, if they are available. These are impaired in high and to a certain extent also in low level paraplegics and do not need energy supply as do amputees and nondisabled individuals. On the other hand their absence restricts work capacity, since the prime moving muscles (arm, shoulder and upper trunk muscles) also need to stabilise the trunk during armcranking. In wheelchair exercise, the trunk is usually well stabilised (except for high gradient uphill wheeling or treadmill exercise), and therefore it seems to be better suited to performance evaluation of wheeling tasks. The findings of Lees \& Arthur $^{8}$ confirm extremely high correlations between performance in $100-400 \mathrm{~m}$ sprints and PANP and MANC determined during 30-second wheelchair ergometric exercise $(r=$
$-.856--.947)$.

Another interesting finding of this study is the very high correlation found between the response to different wheeling tasks, the slalom (about one minute duration) and the min6 test $(r=-.967)$. These activities are within the span of activities (1-8 minutes duration) whose limiting factor is the ability to tolerate high concentrations of lactic acid. This limiting factor should be considered for evaluation in future investigations. ${ }^{7}$

We also investigated the relationship between personal characteristics and test results. The correlations presented in Table II indicate that the less functionally limited subjects are likely to show higher mean work capacities in short term anaerobic armcranking exercise ( $r$ of MANC and class: $.717 ; p=.015)$ and be faster in wheeling tasks of similar durations ( $r$ of race and class: $-.641, p=.031$ ) than their more functionally limited peers.

Another factor detrimental to armcranking performance in our subjects was increased bodyweight. The high correlations computed with MANC and PWC indicate a substantial influence of body mass on the results in both aerobic and anaerobic variables. On the basis of this finding one may suggest that these results be analysed in terms of power relative to bodyweight, similar to the extensive use of oxygen consumption relative to bodyweight in many publications concerning armcranking performance. ${ }^{9-14}$ The differences between absolute (watt) and relative (watt $/ \mathrm{kg}$ ) power measurements in armcranking exercise are displayed in Table IV. These are extremely apparent in aerobic exercise, as described in Fig 1.

On the other hand, the findings of this study do not show any evidence that bodyweight also relates to performance in wheeling tasks of different durations. The use of power output in armcranking exercise as a predictor of functional exercise capacity (wheeling performance) seems therefore to be limited. This result may be explained partially by confounding variables such as wheelchair weight and rolling capacity as well as individual technique, which may have considerable impact on wheeling performance. 
Table IV Absolute vs relative power in aerobic and anaerobic performance of Israeli elite wheelchair basketball players

\begin{tabular}{ccccccccc}
\hline Subject & $\begin{array}{c}\text { Class } \\
\text { (points) }\end{array}$ & $\begin{array}{c}\text { BW } \\
\text { (kg) }\end{array}$ & $\begin{array}{c}\text { MANC } \\
\text { (watt) }\end{array}$ & $\begin{array}{c}\text { MANC/BW } \\
\text { (watt/kg) }\end{array}$ & $\begin{array}{c}\text { PANP } \\
\text { (watt) }\end{array}$ & $\begin{array}{c}\text { PANP/BW } \\
\text { (watt/kg) }\end{array}$ & $\begin{array}{c}\text { PWC } \\
\text { (watt) }\end{array}$ & $\begin{array}{c}\text { PWC/BW } \\
\text { (watt/kg) }\end{array}$ \\
\hline 1 & 3.0 & 87 & 310.59 & 3.57 & 357.00 & 4.10 & 137.25 & 1.58 \\
2 & 4.0 & 83 & 370.20 & 4.46 & 432.94 & 5.22 & 168.24 & 2.03 \\
3 & 1.0 & 70 & 304.71 & 4.35 & 411.76 & 5.88 & 125.00 & 1.79 \\
4 & 4.0 & 73 & 394.12 & 5.40 & 476.47 & 6.53 & 103.92 & 1.42 \\
5 & 2.0 & 75 & 308.82 & 4.12 & 370.59 & 4.26 & 113.73 & 1.31 \\
6 & 3.0 & 62 & 301.47 & 4.86 & 367.65 & 5.93 & 102.94 & 1.66 \\
7 & 1.5 & 51 & 212.42 & 4.17 & 245.10 & 4.81 & 104.71 & 2.05 \\
8 & 4.0 & 90 & 407.84 & 4.53 & 489.41 & 5.44 & 146.57 & 1.63 \\
9 & 4.0 & 74 & 305.88 & 4.13 & 388.24 & 5.25 & 105.39 & 1.42 \\
\hline
\end{tabular}

$\mathrm{BW}=$ bodyweight .

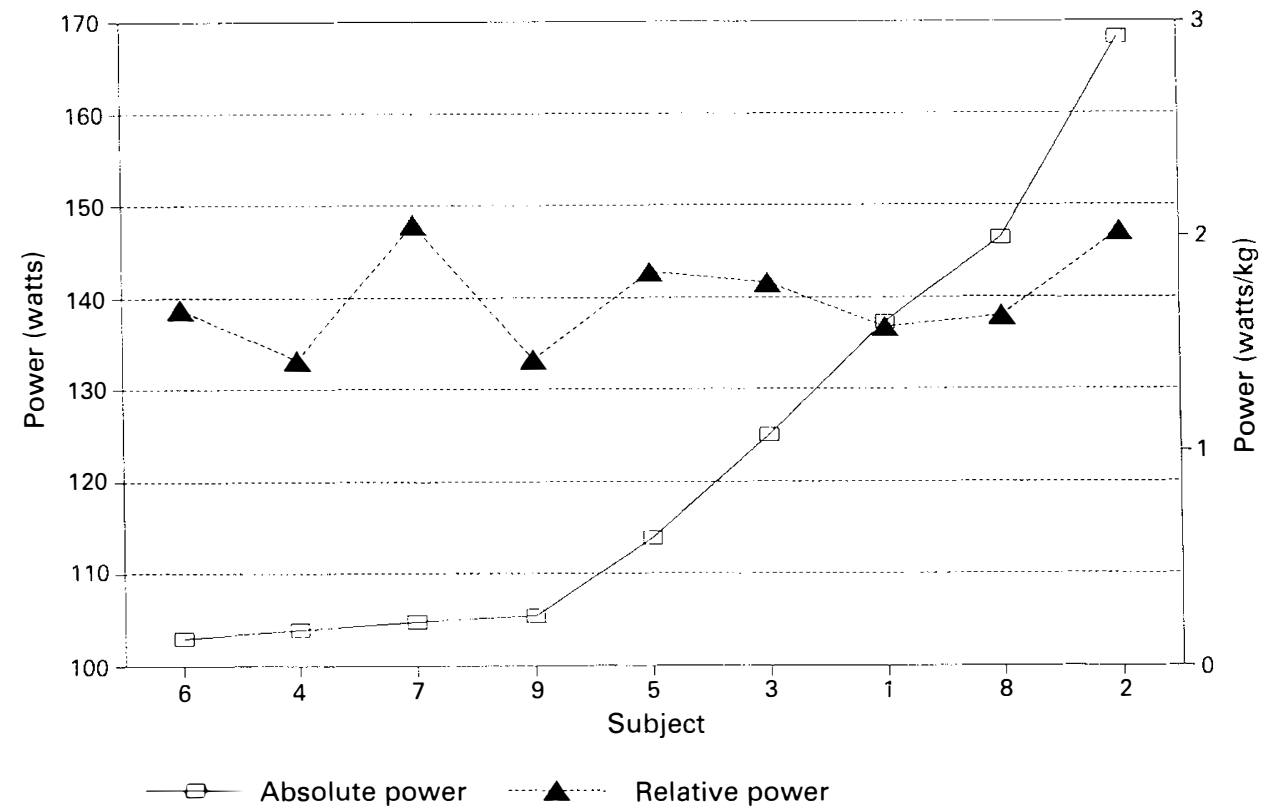

Figure 1 Peak aerobic capacity in armcranking: absolute vs relative power of elite Israeli wheelchair basketball players.

\section{References}

1 Shephard RJ (1990) Fitness in special populations. Human Kinetics. Champaign, Illinois.

2 Wells CL, Hooker SP (1990) The spinal injured athlete. Adapted Physical Activity Q 7: 265-285.

3 Bar-Or O, Inbar O, Dotan R (1976) Proficiency, speed and endurance test for wheelchair bound. Paper presented at the international seminar on motor learning in physical education and sport, Netanya, Wingate Institute, April 1976.

4 Coutts KD, Stogryn JL (1987) Aerobic and anaerobic power of Canadian wheelchair track athletes. Med Sci Sport Exerc 20(2): 188-194.

5 Bar-Or O, Zwirn L (1975). Maximal oxygen consumption test during arm exercise-reliability and validity. $J$ Appl Physiol 38(3): 424-426.

6 Kofsky PR, Davis GM, Shephard RJ, Jackson RW, Keene GCR (1983) Field testing: assessment of physical fitness of disabled adults. Eur J Appl Physiol 51: 109-120. 
7 Skinner JS Morgan DW (1985) Aspects of anaerobic performance. In: American Academy of Physical Education, editor. Limits of Human Performance. Eugene, Oregon.

8 Lees A, Arthur S (1988) An investigation into anaerobic performance of wheelchair athletes. Ergonomics 31(11): 1529-1537.

9 Burke EJ, Auchinachie JA, Hayden R, Loftin JM (1985) Energy cost of wheelchair basketball. Physician Sport Med 13(3), 99-105.

10 Glaser RM, Sawka MN, Brune MP, Wilde SW (1980) Physiological responses to maximal effort wheelchair and arm crank ergometry. J Appl Physiol 48(6): 1060-1064.

11 Goswami A, Gohsh AL, Ganguli S, Banerjee AK (1984) Aerobic capacity of severely disabled Indians. Ergonomics 27: 1267-1269.

12 Hjeltnes N (1980) Control of medical rehabilitation of para and tetraplegics. In: H Natvig, editor. The first international congress on sports for the disabled. Royal Ministry of Church and Education, Oslo: 162-173.

13 Jackson RW, Davis GM, Kofsky PR, Shephard RJ, Keene GCR (1981) Fitness levels in the lower limb disabled. Abstract. Transactions of the twenty seventh annual meeting, Orthopedics Research Society, 6.

14 Zwirn LD, Bar-Or O (1975) Responses to exercise of paraplegics who differ in conditioning level. Med Sci Sport Exerc 7(2): 94-98. 